\title{
BMJ Open Knowledge, attitude and practice of evidence-based medicine among primary care practitioners in Malaysia: a cross-sectional study
}

\author{
Mat Nawi Zanaridah, Mohd Noor Norhayati (D) , Zakaria Rosnani
}

To cite: Zanaridah MN, Norhayati MN, Rosnani Z. Knowledge, attitude and practice of evidence-based medicine among primary care practitioners in Malaysia: a cross-sectional study. BMJ Open 2021;11:e044372. doi:10.1136/ bmjopen-2020-044372

- Prepublication history for this paper is available online. To view these files, please visit the journal online (http://dx.doi. org/10.1136/bmjopen-2020044372).

Received 03 September 2020 Accepted 19 May 2021
Check for updates

(c) Author(s) (or their employer(s)) 2021. Re-use permitted under CC BY-NC. No commercial re-use. See rights and permissions. Published by BMJ.

Department of Family Medicine, Universiti Sains Malaysia,

Health Campus, Kubang Kerian, Malaysia

Correspondence to

Professor Mohd Noor Norhayati; hayatikk@usm.my

\section{ABSTRACT}

Objectives To determine the level of knowledge and practice of evidence-based medicine (EBM) and the attitudes towards it and to identify the factors associated with its practice among primary care practitioners in Selangor, Malaysia.

Setting This cross-sectional study was conducted in randomly selected health clinics in Selangor. Data were collected from primary care physicians using selfadministered questionnaires on knowledge, practice and attitudes regarding EBM.

Participants The study included 225 respondents working in either government or private clinics. It excluded house officers and those working in public and private universities or who were retired from practice.

Results A total of $32.9 \%$ had a high level of EBM knowledge, $12 \%$ had a positive attitude towards EBM and $0.4 \%$ had a good level of its practice. The factors significantly associated with EBM practice were ethnicity, attitude, length of work experience as a primary care practitioner and quick access to online reference applications on mobile phones.

Conclusions Although many physicians have suboptimal knowledge of EBM and low levels of practising it, majority of them have a neutral attitude towards EBM practice. Extensive experience as a primary care practitioner, quick access to online references on a mobile phone and good attitude towards EBM were associated with its practice.

\section{BACKGROUND}

Since the introduction of evidence-based medicine (EBM), several cross-sectional studies have been conducted in various countries to assess knowledge and attitudes regarding EBM and its practice by medical staff and students. A study of 302 general practitioners in England showed that $40 \%$ were aware of the Cochrane Database of Systematic Reviews, $52 \%$ of Bandolier and $60 \%$ of the Effective Health Care Bulletins. The study concluded that doctors had a low level of awareness of extracting journals, review publications and databases. ${ }^{1}$

A study of 398 physicians in different specialties in a teaching hospital found that $10.5 \%$
Strengths and limitations of this study

- This is the first study to explore the knowledge, attitude and practice and the associated factors for evidence-based medicine in Malaysia.

- The study applies a new, validated questionnaire on knowledge, practice and attitudes regarding evidence-based medicine.

- The study was conducted in a densely populated state involving government and private primary care practitioners.

- The high patient workload might pressure primary care practitioners to complete the questionnaire.

have good EBM knowledge. In contrast, $54 \%$ and $35.5 \%$ of the study population had adequate and poor knowledge, respectively. Regarding attitudes towards EBM, $76.4 \%$ of the physicians welcomed the current promotion of EBM and $89.9 \%$ thought that practising EBM improved patient outcomes. The barriers to practising EBM were patient overload $(68.1 \%)$, lack of tie $(60.1 \%)$, colleagues' attitude $(47 \%)$, lack of skills $(46.7 \%)$ and fear of criticism $(44.5 \%){ }^{2}$

Lack of time has been a common barrier reported among physicians for the past 20 years. ${ }^{23}$ It has been suggested that for clinicians to have a good grasp of EBM, they would need to read at least 19 original articles every day of the year. ${ }^{4}$ In contrast, near a decade ago, authors suggested that clinicians should spend 1 hour a week searching for and reading evidence to apply to daily practice. ${ }^{5}$ In recent years, the increased adoption of smartphones by physicians demonstrates the opportunity to access information systems and clinical tools to facilitate the practice of EBM at the point of care. ${ }^{6}$ No study has found a significant relationship between factors associated with poor clinical practice of EBM; instead, they have addressed only the prevalence of factors that support or impede 
its implementation. This study aimed to determine the level of knowledge and practice of EBM and the attitudes towards it and to identify the factors associated with its practice among primary care practitioners in Selangor, Malaysia.

\section{METHODOLOGY \\ Population and sample}

This cross-sectional study included primary care practitioners in Selangor, including all private general practitioners, government medical officers and family medicine specialists. It also included those working in either government or private clinics. It excluded house officers and those working in public and private universities as the work setting is already conducive for EBM training and practices.

Simple random sampling by computer-generated application was applied to a list of primary care physicians' names from all clinics in the state. The sample size was calculated for the prevalence of a high level of knowledge of EBM using a single proportion formula. ${ }^{7}$ In the pilot study, this prevalence was $27.8 \%$. After considering the study's feasibility, a precision of 0.06 was applied with $95 \%$ confidence and a non-response rate of $10 \%$. A sample of 237 primary care practitioners was required.

\section{Questionnaire development}

Questionnaire development involved various stages, including extensive literature search on the topic of interest, identifying the content validity with a panel of expert and presurvey evaluation through cognitive debriefing to assess for clarity and understanding. Further details of developing and validating the EBM questionnaire are described elsewhere. ${ }^{8}$ The EBM knowledge domain's 15 items used 3-point Likert scale (correct=3, not sure=2, wrong=1) with Cronbach's alpha of 0.81 . The attitude domain's 17 items used 5-point Likert scale (strongly agree $=5$, agree $=4$, neutral $=3$, disagree $=2$, strongly disagree $=1$ ) with Cronbach's alpha of 0.81 . Similarly, the practice domain's 11 items used the same 5-point Likert scale with Cronbach's alpha of 0.84 . The per cent score for each domain was categorised using Bloom's cutoff point $(60 \%-80 \%),{ }^{9}$ as in other studies. ${ }^{10-12}$ Within this range, scores were said to have moderate, neutral and fair levels of knowledge, attitude and practice, respectively. Neutral means that the respondents neither 'agree' nor 'disagree' with the items. It places them into neither 'positive' nor 'negative' attitude in general. Scores above this cut-off point were equated to high level, positive and good knowledge, attitude and practice. Scores below this cut-off point were equated to low level, negative and poor knowledge, attitude and practice.

\section{Data collection}

Data collection was conducted from February to May 2019. After the eligible participants were identified using stratified proportionate random sampling, the researcher made appointments with the prospective participants at their respective facilities, explained the study and distributed the informed consent forms. When the participants understood and consented to join the study, they were given the self-administered questionnaire and were free to ask the researcher if questions arose while answering it. The questionnaires were checked for completeness, and the participants were thanked for their cooperation.

\section{Data entry and analyses}

The data were entered and analysed using IBM SPSS Statistics V.24.0. Descriptive analyses were conducted to determine a high level of knowledge, a positive attitude and a good practice of EBM. Simple and general linear regressions were used to determine the factors associated with EBM practice scores.

We applied simple linear regression to determine the potential associated factor for practice score on EBM. Subsequently, we applied general linear regression to find the significant associated factors while controlling for other confounders in the model. The predictors were determined based on clinical judgement and statistical significance of $p<0.3$ in simple linear regression. The $p$ value was set as such for screening variables in simple linear regression before being selected into the subsequent analysis of general linear regression. Simple linear regression was done on all independent variables at the univariable level. The analysis was continued with general linear regression. Variable selection was done by automatic backward and forward stepwise procedure. Interaction and multicollinearity were checked. All possible two-way interaction terms and multicollinearity of the variables were checked. The model assessment was done by checking the linearity, equal variance and normality assumption as well as outliers by using standardised residual plots. Findings were presented with crude and adjusted regression coefficient, $95 \% \mathrm{CI}$ and $\mathrm{p}$ value. The level of significance was set at 0.05 in a two-tailed fashion.

\section{Patient and public involvement}

It was not appropriate or possible to involve patients or the public in the design, or conduct, or reporting or dissemination plans of our research.

\section{RESULTS}

Of the 237 respondents invited to participate in the study, 225 participated, a rate of $94.9 \%$. The other 12 were excluded from further analyses because they either failed to participate or did not complete the questionnaires. The sociodemographic profiles of the 225 primary care practitioners are shown in table 1.

Seventy-four respondents $(32.9 \%)$ were classified as having a high level of knowledge. This was followed by moderate $(60.9 \%, \mathrm{n}=137)$ and low $(6.2 \%, \mathrm{n}=14)$ level of knowledge. The knowledge items and the possible responses to them are shown in table 2 . 


\begin{tabular}{|c|c|c|}
\hline Variables & Median (IQR*) & n (\%) \\
\hline Age (year) & $33(4.0)$ & \\
\hline $\begin{array}{l}\text { Duration in current } \\
\text { workplace (year) }\end{array}$ & $5(4.0)$ & \\
\hline \multicolumn{3}{|l|}{ Sex } \\
\hline Male & & $45(20.0)$ \\
\hline Female & & $180(80.0)$ \\
\hline \multicolumn{3}{|l|}{ Ethnicity } \\
\hline Malay & & $157(69.8)$ \\
\hline Non-Malay & & $68(30.2)$ \\
\hline \multicolumn{3}{|l|}{ Marital status } \\
\hline Single & & 29 (12.9) \\
\hline Married & & $196(87.1)$ \\
\hline \multicolumn{3}{|c|}{ Highest academic qualification } \\
\hline MBBS/MD/MBChB & & $199(88.4)$ \\
\hline Specialist & & $26(11.6)$ \\
\hline \multicolumn{3}{|l|}{ Place of practice } \\
\hline Government clinic & & $208(92.4)$ \\
\hline Private clinic & & $17(7.6)$ \\
\hline \multicolumn{3}{|c|}{ Average number of patients seen per day } \\
\hline$<20$ & & $18(8.0)$ \\
\hline $21-30$ & & $45(20.0)$ \\
\hline $31-40$ & & $57(25.3)$ \\
\hline $41-50$ & & $46(20.4)$ \\
\hline$>51$ & & $59(26.2)$ \\
\hline
\end{tabular}

Availability of provided internet access in workplace

$\begin{array}{lr}\text { Yes } & 71(31.6) \\ \text { No } & 154(68.4)\end{array}$

Availability of subscribed online databases in workplace

$\begin{array}{lr}\text { Yes } & 71 \text { (31.6) } \\ \text { No } & 154 \text { (68.4) }\end{array}$

Presence of online quick reference application

$\begin{array}{lr}\text { Yes } & 146(64.9) \\ \text { No } & 79(35.1)\end{array}$

\begin{tabular}{lr} 
Presence of continuous medical education in workplace \\
Yes & $195(86.7)$ \\
\hline No & $30(13.3)$ \\
\hline
\end{tabular}

*interquartile range

Twenty-seven respondents (12\%) were classified as having a positive attitude towards EBM. This was followed by neutral $(81.8 \%, \mathrm{n}=184)$ and negative $(6.2 \%, \mathrm{n}=14)$ attitude towards EBM. The attitude items and the possible responses to them are shown in table 3 .

One respondent $(0.4 \%)$ was classified as having a good level of practice. Most respondents had poor level of practice $(84.0 \%, n=189)$, followed by moderate level of practice $(15.6 \%, \mathrm{n}=35)$. The practice items and the percentage of respondents are shown in table 4.

General linear regression showed that ethnicity, attitude towards EBM, length of work experience as a primary care practitioner and having quick access to online reference applications on a mobile phone were significantly associated with EBM practice scores (table 5).

When asked their opinions regarding EBM use, $68.4 \%$ $(\mathrm{n}=154)$ were bound to follow locally available clinical practice guidelines and standard operating procedures, $48.4 \%(\mathrm{n}=109)$ said it was time-consuming, 32\% ( $\mathrm{n}=72)$ thought that expert opinions and practices from experienced consultants were the most critical factors in decision-making, $31.1 \%(\mathrm{n}=70)$ did not understand the research terms, 21.3\% $(\mathrm{n}=48)$ lacked research interest, $17.3 \%(\mathrm{n}=39)$ said that no colleagues or senior doctors practised EBM or guided them to do so, and 8\% ( $n=18)$ cited lack of financial incentive to use EBM.

Only $33.3 \%(n=75)$ had trained on search strategy/ critical appraisal. Among them, $20.9 \%(\mathrm{n}=47)$ did so in college, $10.7 \%(\mathrm{n}=24)$ during continuous medical education, 5.8\% $(\mathrm{n}=13)$ in an online course, $4 \%(\mathrm{n}=9)$ from other methods, which were not explicitly stated, and $3.6 \%$ $(n=8)$ learnt from self-study. In addition, 49.3\% ( $n=111)$ performed online database search meta-analyses/systematic reviews for clinical evidence to manage patients. Of these, $3.1 \%(\mathrm{n}=7)$ searched daily, $9.8 \% \quad(\mathrm{n}=22)$ weekly, $15.6 \%(\mathrm{n}=35)$ monthly, $11.6 \%(\mathrm{n}=26)$ bimonthly, $5.8 \%$ $(n=13)$ biannually and $3.6 \% \quad(n=8)$ annually. Furthermore, $38.2 \%(\mathrm{n}=86)$ accessed online bibliographic databases from home, $13.8 \%(\mathrm{n}=31)$ from hospitals/clinics, $1.3 \%(\mathrm{n}=3)$ from local libraries and $8.4 \%(\mathrm{n}=19)$ from other places. However, $40.4 \%(\mathrm{n}=91)$ did not perform online database searches.

\section{DISCUSSION}

This study was performed among primary care practitioners, of whom $80 \%$ were women. This gender imbalance is commonly seen in primary care settings in industrialised countries. The proportion of female primary care physicians has doubled over the last 30 years. Globally, 32\% of all physicians who graduate worldwide are female, and this percentage is higher, on average, in primary care practice. ${ }^{13}$

\section{Prevalence of good EBM knowledge}

In the present study, $60.9 \%$ had a moderate level of knowledge, $32.9 \%$ had a high level and $6.2 \%$ had a low level. When compared with the results of other studies, most of the reported results showed limited or poor EBM knowledge. Most studies assessed EBM knowledge based on related statistical or technical terms. One systematic review of physicians' knowledge, practice and attitudes regarding EBM included 57 studies of primary care practitioners, residents, specialists and subspecialists. They found that most studies had adopted the McColl questionnaire, four the Fresno test and seven self-developed 
Table 2 Knowledge items with percentage of responses

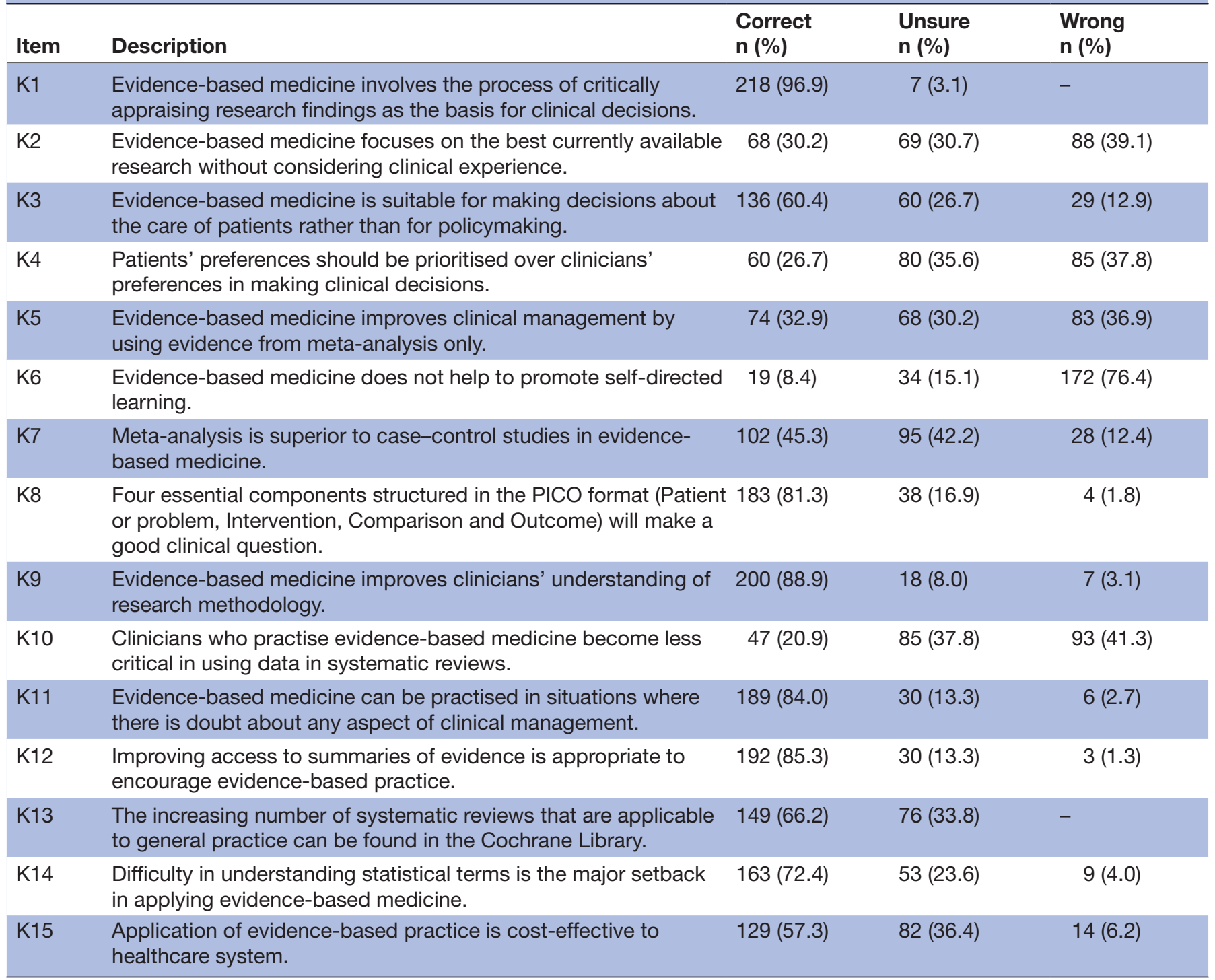

quizzes. As the three tools have different methodologies, a meta-analysis was impossible. ${ }^{14}$

In the present study, the majority understood that EBM involves critically appraising research findings as to the basis for clinical decisions, indicating awareness that EBM does not accept results without critically appraising them systematically. This result is supported by those of an Australian study in which primary care practitioners trained in the critical appraisal were more likely to translate evidence from systematic reviews into practice. ${ }^{15}$

About $60 \%$ believed EBM suitable for making decisions about patient care but not policymaking. However, this is not an accurate understanding of EBM and policymaking. Relevant systematic reviews can help policymakers, clinicians and consumers make informed decisions. Guidelines and reliable research summaries based on sound evidence also help establish professional standards. ${ }^{16}$ One of the WHO's goals for the 21st century is to produce and expand EBM knowledge to policy and implementation. ${ }^{17}$
Regarding the item about influences of decision-making in clinical settings, $37.8 \%$ disagreed that patients' preferences should be considered first before clinicians' preferences. To make a clinical decision, the physicians will recall their experiences with previous patients. Then, they will divide those patients into collections of subgroups or series and make a comparison with the present patient clinical condition. ${ }^{18}$ However, EBM is an integration of clinical expertise with the best available evidence from systematic research with consideration of patients' preferences. ${ }^{19}$ In other words, clinical expertise does not belong within the evidence hierarchy's decision-making pyramid. Rather, it is represented as a complementary source of knowledge, with consideration of patients' preferences, that supports the process of EBM. ${ }^{20}$

The majority knew that EBM has four essential components structured in the PICO format (Patient or problem, Intervention, Comparison and Outcome), which is a framework to formulate clinical questions. ${ }^{21}$ Previous 
Table 3 Attitude items with percentage of responses

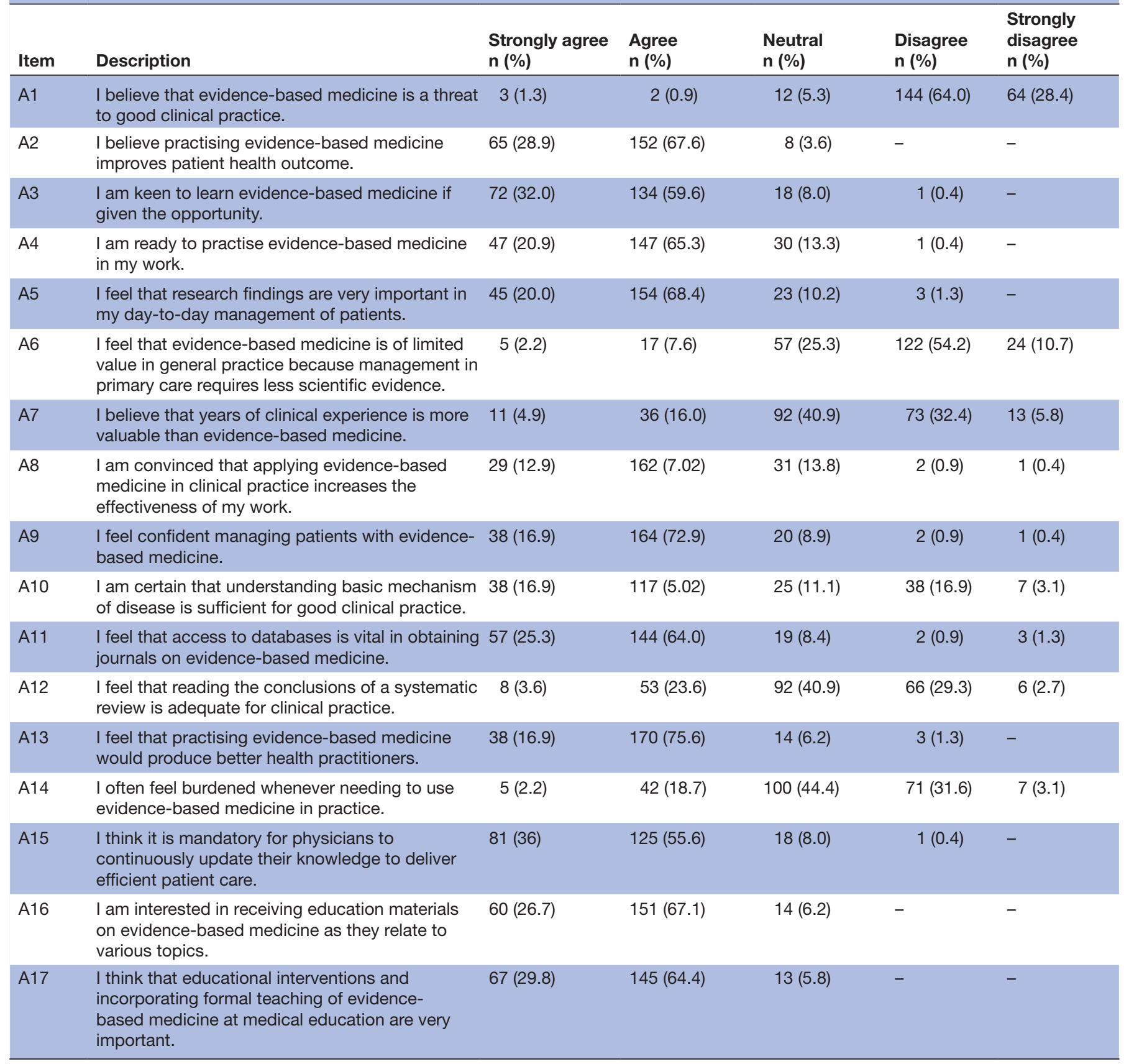

studies, including two systematic reviews, did not test PICO use to assess EBM knowledge, but tested standard terms used in the literature. ${ }^{11422}$ The PICO framework has been tested and found adequate and suitable for representing knowledge for clinical questions. ${ }^{21}$

In the present study, most had difficulty understanding statistical terms, which impeded EBM practice. This was further indicated by the $42.2 \%$ who were unsure whether a meta-analysis is superior to a case-control study in EBM, showing that they did not understand terms common in the EBM literature. This result was supported by those of a study in Melaka that found that a majority did not understand the terms 'number needed to treat', 'metaanalysis', 'odds ratio' and 'confidence interval', although the majority had some understanding of 'relative risk' and 'absolute risk'. ${ }^{23}$ In comparison, less than $38 \%$ of medical officers understood 'systematic review' and 'metaanalysis' and that understanding of 'number needed to treat' and 'risk difference' was poor. ${ }^{16}$ A study found that most had some knowledge of the technical terms used in EBM and that one-third could explain their meaning to others. ${ }^{1}$ These results indicate that local doctors are not well exposed to the commonly used terms in the scientific literature compared with those in other countries. There is a measurable disconnection between what physicians should know before starting clinical practice and what they actually do know. To narrow this gap, there is a need to make EBM training mandatory in both undergraduate 
Table 4 Practice items with percentage of responses

\begin{tabular}{|c|c|c|c|c|c|c|}
\hline Item & Description & $\begin{array}{l}\text { Always } \\
\text { n (\%) }\end{array}$ & $\begin{array}{l}\text { Often } \\
\mathrm{n}(\%)\end{array}$ & $\begin{array}{l}\text { Sometimes } \\
\text { n (\%) }\end{array}$ & $\begin{array}{l}\text { Seldom } \\
\text { n (\%) }\end{array}$ & $\begin{array}{l}\text { Never } \\
\text { n (\%) }\end{array}$ \\
\hline P1 & I apply evidence-based medicine in practice. & $7(3.1)$ & $101(44.9)$ & $99(44.0)$ & $16(7.1)$ & $2(0.9)$ \\
\hline P3 & $\begin{array}{l}\text { I search for evidence-based medicine } \\
\text { material from published journals only. }\end{array}$ & $12(5.3)$ & $58(25.8)$ & $98(43.6)$ & $51(22.7)$ & $6(2.7)$ \\
\hline P5 & $\begin{array}{l}\text { I cannot practise evidence-based medicine } \\
\text { due to limitations of the management that I } \\
\text { can offer to patients in clinical settings. }\end{array}$ & $45(20.0)$ & $79(35.1)$ & $84(37.3)$ & $15(6.7)$ & $2(0.9)$ \\
\hline P6 & $\begin{array}{l}\text { I use evidence-based medicine for answering } \\
\text { the questions in clinical setting. }\end{array}$ & $28(12.4)$ & $105(46.7)$ & $82(36.4)$ & $9(4.0)$ & $1(0.4)$ \\
\hline P8 & $\begin{array}{l}\text { I promote evidence-based practice to my } \\
\text { colleagues at the workplace. }\end{array}$ & $19(8.4)$ & 75 (33.3) & $68(30.2)$ & $40(17.8)$ & $23(10.2)$ \\
\hline P9 & $\begin{array}{l}\text { I share my knowledge on evidence-based } \\
\text { medicine with my colleagues. }\end{array}$ & $18(8.0)$ & $81(36.0)$ & $81(36.0)$ & $32(14.2)$ & $13(5.8)$ \\
\hline P10 & $\begin{array}{l}\text { I am involved in the development of clinical } \\
\text { practice guidelines in Malaysia. }\end{array}$ & $6(2.7)$ & 19 (8.4) & $24(10.7)$ & $18(8.0)$ & $158(70.2)$ \\
\hline P11 & $\begin{array}{l}\text { I usually translate a clinical question into } \\
\text { a form that can be answered from the } \\
\text { literature. }\end{array}$ & $6(2.7)$ & $21(9.3)$ & 75 (33.3) & $54(24.0)$ & $69(30.7)$ \\
\hline
\end{tabular}

and graduate level for future practising physicians to become more proficient in EBM skills.

In the present study, most agreed that improving access to summaries of evidence is appropriate to encourage evidence-based practice. In a study of physicians in the Middle East, $27.4 \%$ perceived a lack of availability of and access to evidence as barriers to EBM practice. ${ }^{24}$ Similar barriers have been reported by medical students and nurses. ${ }^{25}$ In the present study, the majority knew about the availability of the Cochrane Database for evidence searches. However, in Sri Lanka, 30\% of doctors were aware of the Cochrane Database, but only $8.5 \%$ of them currently used it. ${ }^{16}$ In Saudi Arabia, $48.7 \%$ were aware of the database, but only $8.5 \%$ used it. $^{24}$

\section{Prevalence of good attitude towards EBM}

We found that only $12 \%$ and $6.2 \%$ of respondents had positive and negative attitudes, respectively, towards EBM and that the majority had a neutral attitude towards it. The results regarding positive attitudes were lower than in other studies. For example, in Sri Lanka, more than $70 \%$ of the respondents had a positive attitude towards EBM and the rest had a negative one. ${ }^{16}$ Another study, which reported responses using a Likert scale based on a median, reported that the majority had a positive attitude towards EBM. ${ }^{23}$ A similar result was seen in Saudi Arabia, with a median of $70 \%$ having a positive attitude. ${ }^{5}$

In the present study, $96.5 \%$ believed that EBM improved patient health outcomes, a finding consistent with those of studies conducted in Sri Lanka (92.5\%), Jordan (90\%) and Saudi Arabia (90\%). ${ }^{31626}$ In contrast, $41.1 \%$ of Jordanian primary care physicians strongly agreed and $48.9 \%$ agreed that practising EBM improves patient care. ${ }^{26}$

Despite most respondents having a neutral attitude towards EBM, between $32 \%$ and $59.6 \%$ showed some degree of keenness to learn EBM. The responses were similar regarding attitudes towards receiving EBM educational materials and the belief that incorporating EBM into medical education is essential. Besides, $68.4 \%$ agreed that research findings are essential to day-to-day patient management. A similar result was found among Jordanian primary care physicians. ${ }^{26}$

In the present study, $54.2 \%$ disagreed that the value of EBM in primary care management is limited. In the Jordanian survey of primary care physicians, $51 \%$ disagreed that EBM has limited value. ${ }^{26}$ In contrast, in Saudi Arabia, only $18 \%$ disagreed that EBM is of limited value. ${ }^{5}$ In the present study, only $20.9 \%$ agreed that they felt burdened when using EBM in practice. This contrasts with the Jordanian study findings, in which $62.4 \%$ agreed that adopting EBM would place more demands on already-overloaded family practitioners. ${ }^{26}$

\section{Prevalence of good practice of EBM}

In the present study, the good practice of EBM was low, but percentages were similar in most studies. We found that $3.1 \%$ and $12.4 \%$, respectively, used EBM in their clinical practice and to answer questions in clinical settings. 
Table 5 Factors associated with EBM practice among 225 primary care practitioners

\begin{tabular}{|c|c|c|c|c|c|c|}
\hline \multirow[b]{2}{*}{ Variables } & \multicolumn{3}{|l|}{ SLR } & \multicolumn{3}{|l|}{ GLR $^{*}$} \\
\hline & bt $(95 \% \mathrm{Cl})$ & t statistics & $P$ value & Adjusted b $¥(95 \% \mathrm{Cl})$ & t statistics & $P$ value \\
\hline Age (year) & $0.34(-0.000$ to 0.688$)$ & 1.97 & 0.051 & & & \\
\hline $\begin{array}{l}\text { Experience in current work } \\
\text { place (year) }\end{array}$ & 0.47 (0.077 to 0.873$)$ & 2.35 & 0.02 & $0.439(0.064$ to 0.814$)$ & 2.31 & 0.022 \\
\hline \multicolumn{7}{|l|}{ Sex } \\
\hline \multicolumn{7}{|l|}{ Male } \\
\hline Female & $-4.20(-8.370$ to -0.038$)$ & -1.99 & 0.048 & & & \\
\hline \multicolumn{7}{|l|}{ Ethnicity } \\
\hline \multicolumn{7}{|l|}{ Malay } \\
\hline Non-Malay & $2.60(-1.038$ to 6.251$)$ & 1.41 & 0.16 & $3.45(0.042$ to 6.854$)$ & 2 & 0.047 \\
\hline \multicolumn{7}{|l|}{ Marital status } \\
\hline \multicolumn{7}{|l|}{ Single } \\
\hline Married & $0.81(-4.204$ to 5.828$)$ & 0.32 & 0.75 & & & \\
\hline \multicolumn{7}{|c|}{ Highest academic qualification } \\
\hline $\begin{array}{l}\text { MBBS/MD/MBChB } \\
\text { specialist }\end{array}$ & $6.12(0.924$ to 11.316$)$ & 2.32 & 0.021 & & & \\
\hline \multicolumn{7}{|l|}{ Place of practice } \\
\hline \multicolumn{7}{|l|}{ Government clinic } \\
\hline Private clinic & $6.59(0.294$ to 12.896$)$ & 2.06 & 0.04 & & & \\
\hline \multicolumn{7}{|c|}{ Average number of patients seen per day } \\
\hline \multicolumn{7}{|l|}{$<20$} \\
\hline $21-30$ & $-3.03(-10.074$ to 4.013$)$ & -0.85 & 0.397 & & & \\
\hline $31-40$ & $-0.24(-7.068$ to 6.589$)$ & -0.07 & 0.945 & & & \\
\hline $41-50$ & $-0.77(-7.780$ to 6.238$)$ & -0.22 & 0.828 & & & \\
\hline$>51$ & $-2.94(-9.742$ to 3.860$)$ & -0.85 & 0.395 & & & \\
\hline \multicolumn{7}{|c|}{ Availability of provided internet access in workplace } \\
\hline \multicolumn{7}{|l|}{ Yes } \\
\hline No & $-0.64(-4.504$ to 3.225$)$ & -0.33 & 0.745 & & & \\
\hline
\end{tabular}

Availability of subscribed online databases in workplace

\begin{tabular}{|c|c|c|c|c|c|c|}
\hline \multicolumn{7}{|l|}{ Yes } \\
\hline No & $-0.381(-7.395$ to -0.230$)$ & -2.10 & 0.037 & & & \\
\hline \multicolumn{7}{|c|}{ Presence of online quick reference application } \\
\hline \multicolumn{7}{|l|}{ Yes } \\
\hline No & $-0.49(-8.348$ to -1.422$)$ & -2.78 & 0.006 & $-4.67(-8.033$ to -1.317$)$ & -2.74 & 0.007 \\
\hline \multicolumn{7}{|c|}{ Presence of continuous medical education in workplace } \\
\hline \multicolumn{7}{|c|}{ Yes } \\
\hline No & $-1.66(-6.595$ to 3.285$)$ & -0.66 & 0.51 & & & \\
\hline \multicolumn{7}{|c|}{ Knowledge categories } \\
\hline \multicolumn{7}{|l|}{ High level } \\
\hline Moderate level & $-2.83(-9.890$ to 4.229$)$ & -0.79 & 0.43 & & & \\
\hline Low level & $-4.34(-7.768$ to 6.898$)$ & -0.12 & 0.907 & & & \\
\hline \multicolumn{7}{|l|}{ Attitude categories } \\
\hline \multicolumn{7}{|l|}{ Positive attitude } \\
\hline Neutral attitude & $2.53(-4.124$ to 9.173$)$ & 0.75 & 0.455 & & & \\
\hline Negative attitude & 14.59 (6.688 to 22.484$)$ & 3.64 & 0 & 13.46 (5.675 to 21.245$)$ & 3.41 & 0.01 \\
\hline
\end{tabular}

${ }^{*} R^{2}=0.189$; there was no significant interaction and no multicollinearity problem; model assumptions met.

†Crude regression coefficient.

$\ddagger$ Adjusted regression coefficient.

EBM, evidence-based medicine; GLR, general linear regression; SLR, simple linear regression. 
In comparison, less than $10 \%$ of Jordanian primary care physicians used EBM resources in their clinical practice. ${ }^{26}$ EBM updates refer to physicians getting new updates on new diseases and the latest treatment best available for the patients. Continuing medical education (CME) is one platform for physicians to collaborate to select and appraise evidence in an explicit way, summarise them and present comments by clinical experts. In the present study, 94.2\% received EBM updates through CME. This high percentage may be due to a policy of the Malaysian Medical Council requiring physicians to acquire at least 20 credit hours of continuing professional development as a condition of renewing their practice licence annually. ${ }^{27}$ Despite this, nearly $99 \%$ of them claimed they were unable to apply EBM in their clinical setting due to management limitations that can be offered in a clinical setting.

The majority of respondents chose 'sometimes' to indicate their use of multiple search engines to conduct systematic reviews. It may be because some literature is not free and not readily available to the public. Using various search engines may increase the chances of finding articles that are free and accessible.

Nearly half of respondents lacked time to practise EBM, a limitation noted in other studies. A systematic review of physicians' EBM practices noted clinicians' lack of time as a barrier to implementing EBM. ${ }^{14}$ In Melaka, a higher percentage $(72.5 \%)$ of primary care doctors perceived a lack of time as a barrier to practising EBM. ${ }^{23}$ In a local qualitative study, EBM was perceived as demanding resources, including time. ${ }^{28}$

Another reason for low EBM practice rates among our respondents was that clinical settings offer patient management that is limited in investigatory and laboratory tests and medications. Lack of facilities and financial resources in primary care settings have also been noted as barriers to practising EBM. ${ }^{14}$

Although $69.3 \%$ of respondents applied PICO principles when answering clinical questions, only $2.7 \%$ of them 'always' did so. However, most were aware that PICO could be used to create good clinical questions. Nevertheless, the lower percentage who always used it could be explained by Sackett $e t a l \mathrm{~s}^{19}$ conclusion that physicians think they are practising EBM when they are not. A study of Dutch-speaking insurance physicians in Belgium found a lower prevalence, with $21 \%$ having good to perfect knowledge of formulating a PICO question. ${ }^{29}$

One reason why the practice of EBM is low among our respondents was due to limitations in the management that the clinician can offer to patients in clinical settings. This limitation in management can include investigation tests, laboratory tests or medications. Lack of facilities and financial resources in a primary care setting were among the barriers to practising EBM. ${ }^{14}$

\section{Factors associated with poor EBM practice}

Based on the present study's results, we concluded that four factors are associated with poor EBM practice: Malay ethnicity, negative attitude towards EBM, shorter duration of working experience and absence of quick access to online reference applications. The shorter the duration of work experience as a primary care practitioner, the weaker the EBM practice, indicating that experienced clinicians are likely to have had more exposure to EBM, which can occur by reading local clinical practice guidelines, attending CME, participating in conferences and receiving formal EBM training. A study in Hungary reached similar conclusions, finding that healthcare work experience had a significant positive effect $(\mathrm{OR}=1.59$, $95 \%$ CI 1.01 to $2.52, \mathrm{p}=0.048)$ on EBM knowledge. ${ }^{30}$

The present study also found that those of Malay ethnicity self-described as having poor EBM practice. The study's demographic data indicate that Malays constituted $69.8 \%$ of respondents and that those who self-described as non-Malay had higher EBM practice scores. There are no studies with which to compare these findings regarding ethnicity as previous studies did not include it in their demographic data. ${ }^{23} 3132$

The third factor associated with poor EBM practice in this study is the absence of quick online access to reference applications. Clinicians who have such access via mobile phones had improved EBM practices, likely because these resources make EBM practice more practical for clinicians lacking time and workplace facilities, including libraries or computers. One study found that having a quick reference or 'evidence cart' affected decisions about diagnosis and treatment in $81 \%$ of cases, and that of those cases $91 \%$ had successful patient outcomes. ${ }^{33}$ Easily accessible, quick references may aid in rapid decision-making. A widely used evidence-based clinical smartphone tool is UpToDate, which has been useful for practising EBM at the bedside and integrating test results with clinical information. ${ }^{6}{ }^{34}$ In a study in Singapore, 93.4\% of physicians found UpToDate useful and would recommend it to colleagues, and for about three-fifths of them using the application led to changes in patient management decisions. ${ }^{35}$

The fourth factor is attitude towards EBM. We found that the more negative the attitude, the weaker the EBM practice. A study in the USA reported that EBM courses improved medical students' attitudes towards EBM. ${ }^{36} \mathrm{We}$ believe that this aspect is lacking in our medical education system, and in our study only $20.9 \%$ had received formal EBM training in a university.

Before this study, the main barrier noted had been lack of time due to high patient loads. In this study, the average number of patients seen per day was not associated with the poor practice of EBM. This finding is interesting, although it may be incorrect, as the number of patients recorded by the respondents may have been influenced by recall bias. In Sri Lanka, $71 \%$ of specialists and postgraduate students perceived patient load as a barrier to EBM practice. ${ }^{16}$ In a study of family physicians in Jordan, $14.9 \%$ strongly agreed and $47.5 \%$ agreed that EBM places another demand on already-overloaded family practitioners. ${ }^{26}$ However, these studies were based 
on respondents' perceptions rather than statistical data regarding the numbers of patients visiting their centres.

In our study, the absence of CME has not been statistically proven to be associated with poor EBM practice. However, a review of 50 randomised controlled trials on the effectiveness of CME concluded that it could improve clinicians' performance and healthcare outcomes. ${ }^{37}$

\section{Strengths and limitations}

This is the first study to use a new, validated questionnaire on knowledge, practice and attitudes regarding EBM. It was conducted in the most highly populated state in Malaysia, Selangor. It involved randomly selected primary care physicians from both the government and private sectors and all nine districts in Selangor.

This study has several limitations. Primary care physicians in Selangor have high patient workloads and therefore limited time to answer questionnaires, which can lead to non-response bias. The questionnaire relied on respondents' self-rated assessments of their knowledge and beliefs. Participants might have felt pressured into completing the questionnaire or unwilling to divulge deficiencies in their knowledge and skills, all of which might introduce response bias. This study found that those with a negative attitude towards EBM will have a poor practice of EBM. However, we believed that this finding might have social desirability bias as data were gathered from a self-reported questionnaire.

\section{CONCLUSIONS}

Although many physicians have suboptimal knowledge of EBM and low levels of practising it, most of them have a neutral attitude towards its practice. Factors associated with high scores in EBM practice include good attitude towards EBM, more extended work experience as a primary care practitioner and quick access to online references via a mobile phone. This study will be replicated in different Malaysian states and different healthcare specialties to provide a comprehensive overview of EBM knowledge, attitude and practice. It is recommended that the appropriate authorities provide primary care practitioners with broader access to EBM resources, including enhancing medical school curricula to teach students to apply EBM skills, making such skills part of vital medical training assessments and incorporating training on EBM skills into CME.

Contributors MNZ contributed to conception and design, acquisition, analysis and interpretation of data, and drafted the manuscript. MNN contributed to conception and design, analysis and interpretation of data, and revised the manuscript critically for important intellectual content. ZR revised the manuscript critically for important intellectual content. All authors read and approved the final manuscript.

Funding This research was funded by Tabung Insentif Pembangunan Pengajian Siswazah PPSP, Universiti Sains Malaysia.

Competing interests None declared.

Patient consent for publication Not required.

Ethics approval The research proposal was approved by the Human Research Ethics Committee, Universiti Sains Malaysia (Universiti Sains Malaysia/
JEPeM/18040195) and Medical Registration and Ethics Committee, Ministry of Health (NMRR-18-349-40727) on 9 August 2018.

Provenance and peer review Not commissioned; externally peer reviewed.

Data availability statement All data relevant to the study are included in the article.

Open access This is an open access article distributed in accordance with the Creative Commons Attribution Non Commercial (CC BY-NC 4.0) license, which permits others to distribute, remix, adapt, build upon this work non-commercially, and license their derivative works on different terms, provided the original work is properly cited, appropriate credit is given, any changes made indicated, and the use is non-commercial. See: http://creativecommons.org/licenses/by-nc/4.0/.

ORCID iD

Mohd Noor Norhayati http://orcid.org/0000-0002-6372-1476

\section{REFERENCES}

1 McColl A, Smith H, White P, et al. General practitioner's perceptions of the route to evidence based medicine: a questionnaire survey. BMJ 1998;316:361-5.

2 Abdel-Kareem A, Kabbash I, Saied S, et al. Knowledge, practices and attitudes of physicians towards evidencebased medicine in Egypt. East Mediterr Health J 2019;25:82-9.

3 Al-Ansary LA, Khoja TA. The place of evidence-based medicine among primary health care physicians in Riyadh region, Saudi Arabia. Fam Pract 2002;19:537-42.

4 Davidoff F, Haynes B, Sackett D, et al. Evidence based medicine. BMJ 1995;310:1085-6.

5 Khoja TA, Al-Ansary LA. Attitudes to evidence-based medicine of primary care physicians in Asir region, Saudi Arabia. East Mediterr Health J 2007;13:408-19.

6 Mosa ASM, Yoo I, Sheets L. A systematic review of healthcare applications for smartphones. BMC Med Inform Decis Mak 2012;12:67.

7 Daniel WW. Determination of sample size for estimating proportion. In: Biostatistics: a foundation for analysis in the health science. 8th edn. Hoboken, NJ: John Wiley \& Sons, 2005.

8 Norhayati MN, Zanaridah MN. Psychometric properties of the knowledge for evidence-based medicine questionnaire using Rasch measurement model. BioMed Research International 2020.

9 Bloom BS. Taxonomy education. New York: David McKay, 1956.

10 Abdullahi A, Hassan A, Kadarman N, et al. Food safety knowledge, attitude, and practice toward compliance with abattoir laws among the abattoir workers in Malaysia. Int J Gen Med 2016;9:79-87.

$11 \mathrm{Koo} \mathrm{H-C,} \mathrm{B.K} \mathrm{P,} \mathrm{A.T} \mathrm{R,} \mathrm{et} \mathrm{al.} \mathrm{Assessment} \mathrm{of} \mathrm{knowledge,} \mathrm{attitude} \mathrm{and}$ practice towards whole grains among children aged 10 and 11 years in Kuala Lumpur, Malaysia. Int J Food Sci Nutr Diet 2015;4:171-7.

12 Yimer M. Knowledge, attitude and practices of high risk populations on louse- borne relapsing fever in Bahir Dar City, north-west Ethiopia. Science Journal of Public Health 2014;2:15-22.

13 Hedden L, Barer ML, Cardiff K, et al. The implications of the feminization of the primary care physician workforce on service supply: a systematic review. Hum Resour Health 2014;12:32.

14 Barzkar F, Baradaran H. 87: knowledge, attitude, and practice of evidence-based medicine among physicians: a systematic review. BMJ Open 2017;7:bmjopen-2016-015415.87.

15 Kidd MR, Mazza D. Clinical practice guidelines and the computer on your desk. Med J Aust 2000;173:373-5.

16 Abeysena C, Jayawardana P, Wickremasinghe R, et al. Evidencebased medicine knowledge, attitudes, and practices among doctors in Sri Lanka. J Evid Based Med 2010;3:83-7.

17 Avsar UZ, Avsar U, Cansever Z, et al. Evidence based medicine: teaching, learning and practice: results of a cross-sectional study from turkey. J Pak Med Assoc 2014;64:762-5.

18 Knottnerus JA, Tugwell P. Evidence-based medicine: achievements and prospects. J Clin Epidemiol 2017;84:1-2.

19 Sackett DL, Rosenberg WM, Gray JA, et al. Evidence based medicine: what it is and what it isn't. BMJ 1996;312:71-2.

20 Paez A. The "architect analogy" of evidence-based practice: Reconsidering the role of clinical expertise and clinician experience in evidence-based health care. J Evid Based Med 2018;11:219-26.

21 Huang X, Lin J, Demner-Fushman D. Evaluation of PICO as a knowledge representation for clinical questions. AMIA Annu Symp Proc 2006:359-63. 
22 Ghojazadeh M, Azami-Aghdash S, Pournaghi Azar F, et al. A systematic review on barriers, facilities, knowledge and attitude toward evidence-based medicine in Iran. J Anal Res Clin Med 2015;3:1-11.

23 Chan GC, Teng CL. Primary care doctors' perceptions towards evidence-based medicine in Melaka state: a questionnaire study. Med J Malaysia 2005;60:130-3.

24 Baig M, Sayedalamin Z, Almouteri O, et al. Perceptions, perceived barriers, and practices of physicians' towards evidence-based medicine. Pak J Med Sci 2016;32:49-54.

25 Ghojazadeh M, Hajebrahimi S, Azami-Aghdash S, et al. Medical students' attitudes on and experiences with evidence-based medicine: a qualitative study. J Eval Clin Pract 2014;20:779-85.

26 Barghouti F, Halaseh L, Said T, et al. Evidence-based medicine among Jordanian family physicians: awareness, attitude, and knowledge. Can Fam Physician 2009;55:e6-13.

27 MMC. Guidelines on continuing professional development: Malaysian Medical Council, 2018. Available: https://www.mycpd2.moh.gov.my/ attachment/docs/D242392.pdf [Accessed 27 Jan 2020].

28 Hisham R, Liew SM, Ng CJ, et al. Rural doctors' views on and experiences with evidence-based medicine: the freedom qualitative study. PLoS One 2016;11:e0152649.

29 Heselmans A, Donceel P, Aertgeerts B, et al. The attitude of Belgian social insurance physicians towards evidence-based practice and clinical practice guidelines. BMC Fam Pract 2009;10:64
30 Csertő M, Berényi K, Decsi T, et al. Self-reported attitudes, knowledge and skills of using evidence-based medicine in daily health care practice: a national survey among students of medicine and health sciences in Hungary. PLoS One 2019;14:e0225641.

31 Hisham R, Ng CJ, Liew SM, et al. Why is there variation in the practice of evidence-based medicine in primary care? A qualitative study. BMJ Open 2016;6:e010565.

32 Lai NM, Teng CL, Lee ML. The place and barriers of evidence based practice: knowledge and perceptions of medical, nursing and allied health practitioners in Malaysia. BMC Res Notes 2010;3:279.

$33 \mathrm{Kang} \mathrm{H}$. How to understand and conduct evidence-based medicine. Korean J Anesthesiol 2016;69:435.

34 Serdar MA, Turan M, Cihan M. Rapid access to information resources in clinical biochemistry: medical applications of personal digital assistants (PDA). Clin Exp Med 2008;8:117-22.

35 Phua J, Lim TK. How residents and interns utilise and perceive the personal digital assistant and UpToDate. BMC Med Educ 2008;8:39.

36 Baum KD. The impact of an evidence-based medicine workshop on residents' attitudes towards and self-reported ability in evidencebased practice. Med Educ Online 2003;8:4329.

37 Davis DA, Thomson MA, Oxman AD, et al. Evidence for the effectiveness of CME. A review of 50 randomized controlled trials. JAMA 1992;268:1111-7. 